\title{
Improvement in Anxiety and Pain After Whole Body Whirlpool Hydrotherapy Among Patients With Myofascial Pain Syndrome
}

\author{
Sang Hee Im, $\mathrm{MD}^{1}$, Eun Young Han, $\mathrm{MD}^{2}$ \\ ${ }^{1}$ Department of Rehabilitation Medicine, Kwandong University College of Medicine, Goyang; \\ ${ }^{2}$ Department of Rehabilitation Medicine, Jeju National University Hospital, Jeju, Korea
}

Objective To evaluate the effect of the Whirlpool hydrotherapy on pain and anxiety in chronic myofascial pain syndrome (MPS) patients, compared to the conventional hydrocollator pack therapy.

Methods Forty-one subjects who have MPS in the upper trapezius muscles without depression were recruited. The patients were randomly assigned into two groups: the whirlpool therapy group whose bodies were immersed in a whirlpool bath at $34^{\circ} \mathrm{C}-36^{\circ} \mathrm{C}$ for 30 minutes; the hydrocollator group who took a 30 -minute application of a standard hot hydrocollator pack. Patients in both groups received therapy three days a week for 2 weeks and underwent several evaluations at baseline and after treatment. The variables we analyzed during evaluations were as follows: the primary outcome we considered was pain severity using a visual analogue scale. And the secondary outcomes examined included anxiety using the Korean version of the Beck Anxiety Inventory and quality of life (QoL) using the Korean version of the World Health Organization QoL Assessment, Brief Form. All follow-up values were compared with the baseline values.

Results The baseline parameters did not show significant differences between two groups. And after 2-week treatment, both groups revealed significant improvement in anxiety levels and QoL, as well as in pain. However, the improvement on pain ( $\mathrm{p}=0.002)$ and anxiety $(\mathrm{p}=0.010)$ was significantly greater in the whirlpool group, compared to the hydrocollator group.

Conclusion The whirlpool hydrotherapy can be used as a more effective therapeutic method to reduce pain and anxiety in chronic MPS patients without depression.

Keywords Hydrotherapy, Myofascial pain syndromes, Anxiety

Received October 8, 2012; Accepted January 22, 2013

Corresponding author: Eun Young Han

Department of Rehabilitation Medicine, Jeju National University Hospital, 15 Aran 13-gil, Jeju 690-767, Korea

Tel: +82-64-717-1672, Fax: +82-64-717-1131, E-mail: clearblue10@naver. com

(c) This is an open-access article distributed under the terms of the Creative Commons Attribution Non-Commercial License (http://creativecommons. org/licenses/by-nc/3.0) which permits unrestricted noncommercial use, distribution, and reproduction in any medium, provided the original work is properly cited.

Copyright $\odot 2013$ by Korean Academy of Rehabilitation Medicine

\section{INTRODUCTION}

Pain is very common component [1] among major public health problems [2] and a compelling reason for seeking medical attention [3]. The definition of pain is 'an unpleasant sensory and emotional experience associated with actual and potential tissue damage, or described in terms of such damage' [4], and pain that persists more 
than 3 months and beyond the expected period of healing is defined as chronic [5].

Several studies have reported about associations between physical and mental problems and comorbidity between mental and somatic disorders in the general population [6-8]. Among mental disorders, depression, and anxiety are commonly associated with pain in primary care [9]. Depression refers to an array of abnormal variations in the mood of a person and is more than just a feeling of being sad or blue and anxiety is described as a feeling of nervousness or uneasiness, which creates a critical disturbance in the mental state.

Myofascial pain is traditionally defined as the localized and referred pain that arises from trigger points in the muscle [10]. Many patients with chronic pain have problems related to muscular conditions and more than one third of those meet the diagnostic criteria for myofascial pain syndrome (MPS) [11]. Chronic MPS patients often complain of considerable physical and psychosocial impairment and distress as well as comorbid conditions such as depression or anxiety [3,8,12-14], which also may perpetuate or aggravate the severity of muscle tension in MPS [15]. Most patients suffering chronic musculoskeletal pain have lower quality of life (QoL), compared with a normal population.

However, the majority of studies placed the emphasis only on the relationship between pain and depression [16]. Little attention has focused on the comorbidity with anxiety and pain and especially research on correlation with anxiety has not been performed in patients with chronic myofascial pain. Furthermore, although hydrotherapy is frequently applied to patients with musculoskeletal pain and enhances muscle relaxation [17], the effects of hydrotherapy have not been recognized for reducing pain and anxiety in patients with MPS.

Therefore, the current study addressed several objectives. First, we evaluated the prevalence of anxiety in chronic MPS patients without depression. Second, we compared MPS patients' pain severity with levels of anxiety. Third, we evaluated the therapeutic effects of hydrotherapy on pain, anxiety, and QoL in chronic MPS patients, and compared the effectiveness of the whirlpool hydrotherapy on pain and anxiety with that of conventional hydrocollator pack therapy. And finally we proposed the results to apply to invigorating the "Human Resource Development Center for Economic Region
Leading Industry" project.

\section{MATERIALS AND METHODS}

\section{Study subjects}

Forty-one subjects who were diagnosed as having MPS in the upper trapezius muscles without depression were recruited from December 1, 2009 to May 31, 2010.

Inclusion criteria were: 1) palpable taut band formed in painful local sites [10] of upper trapezius, 2) pain when the involved muscles were pressed with trigger points causing referred pain [10] at relatively accurate spots around the skeletal muscles, 3 ) limited joint motion because of such pain, 4) duration of pain for at least 3 months, and 5) moderate or greater intensity of pain ( $\geq 4$ on the visual analogue scale [VAS]).

Patients with depression (Beck Depression Inventory $[\mathrm{BDI}]>10$ ), psychiatric disease, impaired cognition (Mini-Mental Status Examination $<24$ ) and severe radiating pain in the upper extremities, or with peripheral neuropathy were excluded from the study. Other exclusion criteria were as follows: abnormal neurologic signs, previous spinal or musculoskeletal fracture or surgery, pregnant women or serious medical illness.

\section{Evaluation}

All patients were assessed the degree of independence during daily activities using the Korean-version of the Modified Barthel Index (K-MBI) [18] for evaluation of the impact of pain on daily life independence at baseline.

And their emotional states were also evaluated using the Korean version of the Beck Depression Inventory (K-BDI) [19]. BDI $[19,20]$ is a 21 -item scale that gathers information on different symptoms of depression. Each item on the scale is scored from 0 to 3 . It provides information on both the presence and severity of depression and higher scores indicate the presence of more severe depression. Patients who have scores above 10 out of 63 were excluded in this study.

The variables evaluated were as follows: the primary outcome we considered was pain severity using a VAS [21]. The VAS for pain consists of three $100-\mathrm{mm}$ lines, each labeled at the left end as 'no pain' $(0 \mathrm{~mm})$ and at the right end as 'very severe pain' (100 $\mathrm{mm}$ ) [21]. Patients were asked to draw a vertical mark on each line, one on the upper line for their current pain, one on the middle 
line for the pain at their best (least painful) period during the previous week, and one on the lower line for the pain at their worst (most painful) period during the previous week.

VAS raw change $\left(\mathrm{VAS}_{\text {follow-up }}-\mathrm{VAS}_{\text {baseline }}\right)$ and percentage change scores [(raw change/VAS $\mathrm{Vaseline}) \times 100$ ] change scores were calculated [22].

And the secondary outcomes examined included anxiety status that was measured using the Korean version of the Beck Anxiety Inventory (K-BAI) [23] and QoL that was scored using the Korean version of the World Health Organization QoL Assessment, Brief Form (K-WHOQOL BREF) $[24,25]$. BAI $[23,26]$ consists of 21 anxiety symptoms, with respondents being asked to indicate the extent to which they were bothered by each item "during the past week, including today". Responses are scored on a 0-3 scale ranging from "not at all" to "severely", giving a score range of $0-63$. As a recommended scoring and interpretation system $[23,26]$ for the BAI, $10-18$ points are classified as mild-moderate anxiety, $19-29$ points as moderate-severe, and 30-63 points as severe anxiety.

The WHOQOL BREF $[24,25,27]$ contains 26 items grouped into five domains of overall QoL including general health, physical health, psychological health, social relationships, and environment. It is based on a Likerttype scale of 1 to 5 . The highest score possible is 130 . Lower scores indicate a lower QoL and higher scores indicate a higher QoL.

All patients were evaluated at the baseline and immediately after 2-week hydrotherapy.

\section{Hydrotherapy (whirlpool vs. hydrocollator pack)}

The patients were randomly assigned into two groups, the whirlpool therapy group or the hydrocollator pack group. The patients in the whirlpool therapy group immersed their whole body, up to the neck, in a whirlpool bath at $32^{\circ} \mathrm{C}-36^{\circ} \mathrm{C}$ for 30 minutes. The whirlpool bath Jetsetter (Hot Spring Spas NZ Ltd., Auckland, New Zealand) are composed of 14 jets ( 2 sets of 1 Motor-Massage DX jet, 1 Jetstream jet, 2 rotary hydromassage jets, 1 directional hydromassage jets, 4 Hydro Stream jets, and 4 directional Precision jets). The bathroom temperature was maintained at around $28^{\circ} \mathrm{C}-30^{\circ} \mathrm{C}$ to prevent heat loss from their bodies.

The control group took a 30-minute application of a standard hot hydrocollator pack on the affected upper trapezius. Hydrocollator pack $(25 \times 30 \mathrm{~cm})$ consisted of hydrophilic silicate gel encased in a canvas outer cover Alkamo (Samwoo Inc., Seoul, Korea). The hydrocollator pack was thermostatically controlled at $74.5^{\circ} \mathrm{C}$ in the hot pack unit model WS302 (Woosin Inc., Seoul, Korea). A commercial terry cloth cover and four or five layers of toweling were used to avoid excessive heat or burn [28].

All patients in both groups took therapy three days a week for 2 weeks and maintained all of their other normal daily habits and medications.

\section{Statistical analysis}

We analyzed the data using the SPSS ver. 12.0 (SPSS Inc., Chicago, IL, USA). Descriptive statistics, such as mean \pm standard deviation or range, were calculated from the data collected. Statistical analyses of parameters including VAS, BAI, and WHOQOL BREF across timepoints were performed using repeated measures analysis of variances. Mann-Whitney test were employed for determination of any significant difference in VAS raw change and VAS percentage change scores. $\chi^{2}$ tests were performed to compare the prevalence of mild to moderate anxiety between two groups. In cases where the anticipated frequency was lower than 5, a Fisher exact test was applied. We calculated Spearman correlation coefficients to examine the relationship between independent and dependent variables. To exclude type 1 error, a p-value $<0.017$ was considered statistically significant.

\section{RESULTS}

Baseline characteristics of the patients between two groups

All patients reported perfect scores in K-MBI and revealed no difficulty in performing daily activity.

The baseline characteristics of the patients are summarized in Table 1. Statistical analysis did not show significant differences in terms of age, gender distribution, the number of patients, baseline severity of pain and anxiety status, and QoL. Twenty-five patients (61.0\%) showed mild to moderate anxiety and there were no significant differences in the number of the patients with mild to moderate anxiety between two groups (whirlpool group, 13; hydrocollator group, 12; $p>0.05$ ). Also, anxiety level correlated with pain severity at baseline $(r=0.525$, $\mathrm{p}<0.001)$. 
Table 1. The baseline characteristics of whirlpool and control groups

\begin{tabular}{lccc}
\hline \multicolumn{1}{c}{ Characteristic } & Whirlpool & Control & p-value \\
\hline Number & 21 & 20 & 0.33 \\
Male:female & $16: 5$ & $12: 8$ & 0.41 \\
Visual analogue scale & $6.81 \pm 2.21$ & $6.05 \pm 1.91$ & 0.25 \\
Beck Anxiety Inventory & $10.57 \pm 4.83$ & $11.25 \pm 4.05$ & 0.63 \\
No. of patients with mild to moderate anxiety & 13 & 12 & 0.58 \\
Quality of life & $72.29 \pm 10.45$ & $71.35 \pm 11.07$ & 0.78 \\
\hline
\end{tabular}

Values are presented as mean \pm standard deviation.

$\mathrm{p}<0.017$.

Table 2. Comparison of pain, anxiety, and QoL by repeated measures analysis of variance

\begin{tabular}{lcccccccc}
\hline & \multicolumn{2}{c}{ Whirlpool group } & & \multicolumn{2}{c}{ Hydrocollator group } & & \multicolumn{2}{c}{ p-value } \\
\cline { 2 - 5 } \cline { 7 - 8 } & Before & After & & Before & After & & $\begin{array}{c}\text { According } \\
\text { to time }\end{array}$ & $\begin{array}{c}\text { According to time } \\
\text { \& type of therapy }\end{array}$ \\
\hline VAS (mm) & $68.1 \pm 22.1$ & $32.9 \pm 28.3$ & $60.5 \pm 19.1$ & $49.0 \pm 14.5$ & & $<0.001^{\text {a) }}$ & $0.002^{\text {a) }}$ \\
BAI (point) & $10.57 \pm 4.83$ & $6.14 \pm 3.85$ & & $11.25 \pm 4.05$ & $10.20 \pm 4.24$ & & $<0.001^{\text {a }}$ & $0.010^{\text {a) }}$ \\
\hline QoL (point) & $72.29 \pm 10.45$ & $78.10 \pm 6.96$ & & $71.35 \pm 11.07$ & $74.25 \pm 8.76$ & & $0.001^{\text {a) }}$ & 0.334 \\
\hline
\end{tabular}

Values are presented as mean \pm standard deviation.

VAS, visual analogue scale; BAI, Beck Anxiety Inventory; QoL, quality of life.

${ }^{\text {a) }} \mathrm{p}<0.017$.

Table 3. Mean change and standard deviation of visual analogue scale (VAS) raw scores and VAS percentage change scores in both groups

\begin{tabular}{lccc}
\hline & Whirlpool & Hydrocollator & p-value \\
\hline$\Delta$ VAS raw & $-35.2 \pm 30.3$ & $-11.5 \pm 12.7$ & $0.012^{\text {a) }}$ \\
$\Delta$ VAS \% & $-52.9 \pm 42.3$ & $-19.3 \pm 20.2$ & $0.011^{\text {a) }}$ \\
\hline
\end{tabular}

${ }^{\mathrm{a})} \mathrm{p}<0.017$.

\section{Changes in parameters after 2-week hydrotherapy}

The primary outcome: pain

Both groups showed significant improvement in the VAS after 2-week treatment (according to time, $\mathrm{p}<0.001$ ) (Table 2). And, VAS scores had been more significantly reduced in the Whirlpool group, compared with those in the hydrocollator pack group (according to time \& type of therapy, $\mathrm{p}=0.002$ ) (Table 2). In addition, there were significant differences of the changes in the raw VAS value ( $\triangle$ VAS raw, $\mathrm{p}=0.012$ ) and percentage $(\triangle \mathrm{VAS} \%, \mathrm{p}=0.011$ ) in the whirlpool group, compared to the hydrocollator group (Table 3 ).

Secondary outcome: anxiety and quality of life

After 2-week treatment, both groups showed significant improvement in the BAI (according to time, $\mathrm{p}<0.001$ ) and WHOQOL BREF scores (according to time, $\mathrm{p}=0.010$ ), compared with baseline (Table 2). BAI scores had been more significantly reduced in whirlpool group, compared with those in the hydrocollator group (according to time \& type of therapy, $\mathrm{p}=0.010$ ) (Table 2). However, WHOQOL BREF scores did not show any significant difference between two groups (according to time \& type of therapy, $\mathrm{p}=0.334$ ) (Table 2).

After 2-week treatment, the number of patients with mild to moderate anxiety had a smaller tendency in the whirlpool group (3 patients, 14.3\%), compared in the hydrocollator pack group (10 patients, $50.0 \%)(p=0.020)$.

\section{DISCUSSION}

We confirmed that majority of patients with chronic MPS had mild to moderate anxiety $[23,26]$ irrespective of depression. Also, we confirmed the effect of hydrotherapy on pain relief and on the improvement of anxiety and that the amount of pain reduction correlated with improvements in BAI.

Chronic pain has been found to be associated with 
various psychiatric disorders including mood, anxiety, somatoform, and personality disorders [29] and the association between chronic pain and depression has received the most research and theoretical attention. Given the prevalence of depression was higher in the chronic pain group compared to the prevalence of anxiety disorders [29] this emphasis is understandable.

On the other hand, there was not shown to be a consistent pattern of association between anxiety disorders and chronic pain [29]. However, McWilliams et al. [16] reported that the association between chronic pain and anxiety disorders, such as panic disorder or post-traumatic stress disorder, was stronger than the association between chronic pain and depression. Therefore, chronic pain should be paid further attention in anxiety.

As already described, we confirmed $61.0 \%$ of patients with chronic MPS revealed mild to moderate anxiety in MPS irrelevant to depression. Also, anxiety level correlated with pain severity at baseline $(\mathrm{r}=0.525, \mathrm{p}<0.01)$. These results suggested the association of pain with anxiety in MPS.

Although Emshoff et al. [22] recommended that mean optimal cutoff points were $-19.5 \mathrm{~mm}$ of VAS raw change and $-35.1 \%$ of VAS percentage change, most clinicians might prefer mean cutoff points at $-30 \mathrm{~mm}$ and $-50 \%$ to best discriminate between patients who experienced treatment success (recovery or important improvement) or not. As this recommendation, our whirlpool group showed important improvement (-35.2 $\mathrm{mm}$ and $-52.9 \%)$ in pain. And it might lead to reduce anxiety.

According to the gate theory, pain is relieved due to the pressure and thermal temperature of hydrotherapy on the skin [30]. Also thermal waters with temperatures above $34^{\circ} \mathrm{C}$ are commonly considered to relax muscles, increase tendon extensibility, dilate blood vessels, and facilitate blood circulation resulting in a wash out of pain mediators and elevation of pain threshold [31].

Although few studies have used hydrotherapy for treating MPS, the effects of hydrotherapy have been widely recognized for reducing labor pain and anxiety $[32,33]$ and reducing symptoms of fibromyalgia or arthritis [3436]. Our study revealed that the whirlpool hydrotherapy had beneficial effects on pain and anxiety in patients with MPS.

On the other hand, as Dubois et al. [37] reported, balneotherapy had shown the improvement of anxiety symptoms in generalized anxiety disorders and low adverse event, compared with paroxetine. Therefore, it might be possible that anxiety reduction preceded pain relief in the whirlpool hydrotherapy.

The WHO defines QoL as an “individual's perception of their position in life in the context of the culture and value systems in which they live and in relation to their goals, expectations, standards and concerns" [38]. Most patients suffering chronic musculoskeletal pain have lower QoL compared with a normal population.

Several studies using various therapeutic approaches for neck and upper-back pain of myofascial origin demonstrated improvements in QoL measures. Lew et al. [39] concluded that an injection of botulinum led to a significant improvement in the bodily pain and mental health scales of the SF-36, compared with control patients. Gur et al. [40] applied low-level laser therapy to 60 patients with MPS and reported significant improvements in patients' QoL. Their conclusions were consistent with our results that both hydrotherapy using the hydrocollator pack and whirlpool led to improve QoL in patients with MPS. However, there was no significant difference between the hydrocollator pack and the whirlpool therapy in our study. Further research should be needed for evaluating the impact on QoL in patients with MPS according to the type of hydrotherapy.

This study had several limitations. First of all, study had a small sample size which limited interpretation of the findings and the precise psychophysiological mechanisms of hydrotherapy remained unknown. Second, our study did not compare the baseline level of anxiety and QoL with control patients without MPS. Third, we did not measure the relaxation of muscle tension and its correlation with pain and anxiety. Forth, the thermal extent of the whirlpool therapy exceeded that of the hydrocollator pack therapy. This might have more beneficial effects on pain reduction in the whirlpool therapy. Finally, we did not verify how long the effects of hydrotherapy would be lasted.

Further well-designed randomized clinical trials should be warranted in the effectiveness of hydrotherapy in various chronic musculoskeletal diseases and other conditions.

In our study, hydrotherapy using Jeju water demonstrated the beneficial effects on pain, anxiety, and QoL management in subjects with MPS and more significant improvement in the severity of pain and anxiety were observed in patients receiving the whirlpool hydrotherapy, 
compared with the hydrocollator pack therapy. We propose the whirlpool hydrotherapy as a scientifically based pain and anxiety management technique in MPS and expect our result to invigorate the "Human Resource Development Center for Economic Region Leading Industry" project.

\section{CONFLICT OF INTEREST}

No potential conflict of interest relevant to this article was reported.

\section{ACKNOWLEDGMENTS}

Following are results of a study on the "Human Resource Development Center for Economic Region Leading Industry" project, supported by the Ministry of Education, Science \& Technology and the National Research Foundation of Korea. The authors gratefully acknowledge Won Jung Jang, PhD.

\section{REFERENCES}

1. Watkins EA, Wollan PC, Melton LJ 3rd, Yawn BP. A population in pain: report from the Olmsted County health study. Pain Med 2008;9:166-74.

2. Martin BI, Deyo RA, Mirza SK, Turner JA, Comstock BA, Hollingworth W, et al. Expenditures and health status among adults with back and neck problems. JAMA 2008;299:656-64.

3. Gureje O, Von Korff M, Simon GE, Gater R. Persistent pain and well-being: a World Health Organization Study in Primary Care. JAMA 1998;280:147-51.

4. Classification of chronic pain. Descriptions of chronic pain syndromes and definitions of pain terms. Prepared by the International Association for the Study of Pain, Subcommittee on Taxonomy. Pain Suppl 1986;3:S1-226.

5. Tuck DC, Okifuji A. Pain terms and taxonomies of pain. In: Fishman SM, Ballantyne JC, Rathmell JP, editors. Bonica's management of pain. 4th ed. Baltimore: Lippincott Williams \& Wilkins; 2010. p. 13-23.

6. Jacobi F, Wittchen HU, Holting C, Hofler M, Pfister $\mathrm{H}$, Muller N, et al. Prevalence, co-morbidity and correlates of mental disorders in the general population: results from the German Health Interview and Examination Survey (GHS). Psychol Med 2004;34:597-611.
7. Jacobi F, Wittchen HU, Holting C, Sommer S, Lieb R, Hofler M, et al. Estimating the prevalence of mental and somatic disorders in the community: aims and methods of the German National Health Interview and Examination Survey. Int J Methods Psychiatr Res 2002;11:1-18.

8. Lowe B, Spitzer RL, Williams JB, Mussell M, Schellberg D, Kroenke K. Depression, anxiety and somatization in primary care: syndrome overlap and functional impairment. Gen Hosp Psychiatry 2008;30:191-9.

9. Toft T, Fink P, Oernboel E, Christensen K, Frostholm L, Olesen F. Mental disorders in primary care: prevalence and co-morbidity among disorders. Results from the functional illness in primary care (FIP) study. Psychol Med 2005;35:1175-84.

10. Simons DG, Travell JG, Simons LS. Myofascial pain and dysfunction: the trigger point manual. 2nd ed. Baltimore: Williams \& Wilkins; 1999.

11. Han SC, Harrison P. Myofascial pain syndrome and trigger-point management. Reg Anesth 1997;22:89101.

12. Verhaak PF, Kerssens JJ, Dekker J, Sorbi MJ, Bensing JM. Prevalence of chronic benign pain disorder among adults: a review of the literature. Pain 1998;77:231-9.

13. Turk DC. Clinical effectiveness and cost-effectiveness of treatments for patients with chronic pain. Clin J Pain 2002;18:355-65.

14. Janosky JE, South-Paul JE, Lin CJ. Pain and depression in a cohort of underserved, community-dwelling primary care patients. J Am Board Fam Med 2012;25:3007.

15. Celiker R, Atalay A, Guven Z. Health-related quality of life in patients with myofascial pain syndrome. Curr Pain Headache Rep 2010;14:361-6.

16. McWilliams LA, Cox BJ, Enns MW, Clara IP. Personality correlates of outpatient mental health service utilization: findings from the U.S. national comorbidity survey. Soc Psychiatry Psychiatr Epidemiol 2006;41:357-63.

17. Hall J, Swinkels A, Briddon J, McCabe CS. Does aquatic exercise relieve pain in adults with neurologic or musculoskeletal disease? A systematic review and meta-analysis of randomized controlled trials. Arch Phys Med Rehabil 2008;89:873-83.

18. Jung HY, Park BK, Shin HS, Kang YK, Pyun SB, Paik NJ, et al. Development of the Korean version of Modified 
Barthel Index (K-MBI): multi-center study for subjects with stroke. J Korean Acad Rehabil Med 2007;31:28397.

19. Rhee MK, Lee YH, Jung HY, Choi JH, Kim SH, Kim YK, et al. A standardization study of Beck Depression Inventory II Korean version (K-BDI): validity. Korean J Psychopathol 1995;4:96-104.

20. Beck AT, Steer RA, Carbin MG. Psychometric properties of the Beck Depression Inventory: twenty-five years of evaluation. Clin Psychol Rev 1988;8:77-100.

21. Boonstra AM, Schiphorst Preuper HR, Reneman MF, Posthumus JB, Stewart RE. Reliability and validity of the visual analogue scale for disability in patients with chronic musculoskeletal pain. Int J Rehabil Res 2008;31:165-9.

22. Emshoff R, Bertram S, Emshoff I. Clinically important difference thresholds of the visual analog scale: a conceptual model for identifying meaningful intraindividual changes for pain intensity. Pain 2011;152:227782.

23. Yook SP, Kim ZS. A clinical study on the Korean version of Beck Anxiety Inventory: comparative study of patient and non-patient. Korean J Clin Psychol 1997;16:185-97.

24. Rhee MK, Lee YH, Park SH, Sohn CH, Chung YC, Hong SK, et al. A standardization study of Beck Depression Inventory I Korean version (K-BDI): reliability and factor analysis. Korean J of Psychopathology 1995;4:77-95.

25. Min SK, Kim KI, Lee CI, Jung YC, Suh SY, Kim DK. Development of the Korean versions of WHO Quality of Life scale and WHOQOL-BREF. Qual Life Res 2002;11:593-600.

26. Creamer M, Foran J, Bell R. The Beck Anxiety Inventory in a non-clinical sample. Behav Res Ther 1995;33:477-85.

27. Skevington SM, Lotfy M, O'Connell KA; WHOQOL Group. The World Health Organization's WHOQOLBREF quality of life assessment: psychometric properties and results of the international field trial. A report from the WHOQOL group. Qual Life Res 2004;13:299310.

28. Myrer JW, Measom G, Durrant E, Fellingham GW. Cold- and hot-pack contrast therapy: subcutaneous and intramuscular temperature change. J Athl Train 1997;32:238-41.
29. Dersh J, Polatin PB, Gatchel RJ. Chronic pain and psychopathology: research findings and theoretical considerations. Psychosom Med 2002;64:773-86.

30. Melzack R, Wall PD. Pain mechanisms: a new theory. Science 1965;150:971-9.

31. Weber BC, Hoppe KM. Physical agent modalities. In: Braddom RL, editor. Physical medicine \& rehabilitation. 4th ed. Philadelphia: Saunders; 2011. p. 449-67.

32. Benfield RD, Hortobagyi T, Tanner CJ, Swanson M, Heitkemper MM, Newton ER. The effects of hydrotherapy on anxiety, pain, neuroendocrine responses, and contraction dynamics during labor. Biol Res Nurs 2010;12:28-36.

33. Benfield RD. Hydrotherapy in labor. J Nurs Scholarsh 2002;34:347-52.

34. Bender T, Karagulle Z, Balint GP, Gutenbrunner C, Balint PV, Sukenik S. Hydrotherapy, balneotherapy, and spa treatment in pain management. Rheumatol Int 2005;25:220-4.

35. McVeigh JG, McGaughey H, Hall M, Kane P. The effectiveness of hydrotherapy in the management of fibromyalgia syndrome: a systematic review. Rheumatol Int 2008;29:119-30.

36. Yurtkuran M, Yurtkuran M, Alp A, Nasircilar A, Bingol U, Altan L, et al. Balneotherapy and tap water therapy in the treatment of knee osteoarthritis. Rheumatol Int 2006;27:19-27.

37. Dubois O, Salamon R, Germain C, Poirier MF, Vaugeois $\mathrm{C}$, Banwarth $\mathrm{B}$, et al. Balneotherapy versus paroxetine in the treatment of generalized anxiety disorder. Complement Ther Med 2010;18:1-7.

38. The World Health Organization Quality of Life assessment (WHOQOL) group. The World Health Organization Quality of Life assessment (WHOQOL): position paper from the World Health Organization. Soc Sci Med 1995;41:1403-9.

39. Lew HL, Lee EH, Castaneda A, Klima R, Date E. Therapeutic use of botulinum toxin type A in treating neck and upper-back pain of myofascial origin: a pilot study. Arch Phys Med Rehabil 2008;89:75-80.

40. Gur A, Sarac AJ, Cevik R, Altindag O, Sarac S. Efficacy of $904 \mathrm{~nm}$ gallium arsenide low level laser therapy in the management of chronic myofascial pain in the neck: a double-blind and randomize-controlled trial. Lasers Surg Med 2004;35:229-35. 